MATEC Web of Conferences 22,04005 (2015)

DOI: $10.1051 /$ matec conf/ 20152204005

(C) Owned by the authors, published by EDP Sciences, 2015

\title{
Research on the Key Technology of Hinge Joint Diseases Treatment without Traffic Interruption for Plate Girder Bridge
}

\author{
Jingchuan Xun \\ Chang'an University, Xi'an, Shaanxi, China
}

Hongwei Xiang

Hebei Provincial communications Planning \& Design institute, Shijiazhuang, Hebei, China

Jingrong Peng

Chang'an University, Xi'an, Shaanxi, China

\begin{abstract}
The plate girder bridge accounts for a large proportion of bridge types for its advantages of simple structure and convenience in construction. However, during the service stage, it is easy to suffer the hinge joint diseases, which badly weaken the integral rigidity of superstructure and affect the operation safety of the bridge. This paper presents a treatment technology for hinge joint diseases without interrupting traffic, and the main operation steps and key points of the technology are summarized. Through an example of the reinforcement of a plate girder bridge, the deformation data before and after the reinforcement is measured and compared, which verifies the effectiveness of the method.
\end{abstract}

Keywords: plate girder bridge, hinge joint diseases, glue-injection, reinforcement measure

\section{INTRODUCTION}

The concrete hollow plate bridge has been widely-used because of its light weight, good structural performance, convenience in construction and many other favorable factors that make it become one of the commonly-used types in medium and small span bridges. The Plate girder bridge is transversely hinged between each plate by cast-in-place grooved concrete or connected by welding of steel plates to make each plate girder work together. It also makes the local load assigned to each plate beam to jointly participate in the bear. Compared with a single beam, the bearing of the whole beams can be significantly multiplied in this method. However, with the rapid development of transportation, especially the rapid growth of overloading vehicles, the damage of the hinge joints of the hollow plate beam bridges comes in different degrees, including the hinge joint seepage, shedding, and even the emergence of single plate bearing.

The single plate bearing is a kind of common and dangerous disease, and its main performance is that the plate produces an obvious elastic deflection and forms a displacement among adjacent plate beams when the heavy vehicles are going through the "single plate". After a heavy truck passes, the deflection will be eliminated, and the plate beam returns to the original shape. Due to the "single plate bearing", the bridge mechanical properties and the driving comfort, the safety and the durability have been significantly reduced. They even affect the operation safety of the bridge.

\section{CONSTRUCTION TECHNOLOGY OF HINGE JOINT GLUE-INJECTION REINFORCEMENT}

The main purpose of hinge joint glue-injection reinforcement is to remove the spoiled hinge joint and inject the glue. Thus, it can form a new hinge joint. The construction steps and key points are shown as follows.

\subsection{Hinge joint treatment}

The treatment includes the joint cleaning and drilling At first, the bottom concrete of hinge joint should be cleaned by electric hammer or other tools; then, the electric wire brushing is used to clean up the seams on both sides. In order to ensure the quality of the glue injection reinforcement, all concretes should be cleaned as far as possible to reach the fracture height the hinge joint has more clean bonding surface.

The main reason of drilling is that the height of injecting glue is high. With the increase of the glue height, the glue injection pressure will be reduced, which will weaken the glue injection effect. The separation distance of drilling can be taken along the beam. It is in equal interval arrangement and ranging from $50 \mathrm{~cm}$ to $150 \mathrm{~cm}$. And its height ranges from $30 \mathrm{~cm}$ to $40 \mathrm{~cm}$. The drilling is shown in Figure 1 and Figure 2.

\subsection{Bury injection pipe and overflow pipe}

Injection pipe and overflow pipe are made of PVC will be set in the clean hinge joint. The interval dis- 


\section{MATEC Web of Conferences}

tance of the pipe is $2 \mathrm{~m}$, and its embedded depth of the injection pipe should be in the range of $1 \mathrm{~cm} 2 \mathrm{~cm}$ from the joint bottom, which is $3 \mathrm{~cm}$ below the injection pipe. With the sealing glue, the injection pipe and overflow pipe can be fixed. The beam ends are closed by polyurethane and wood, whose depth should be close to the bottom surface of the hinge joint filler, and the contact should be tight to prevent the leakage of glue.

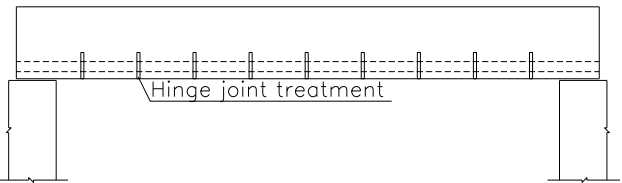

Figure 1. Elevating drawing of drilling

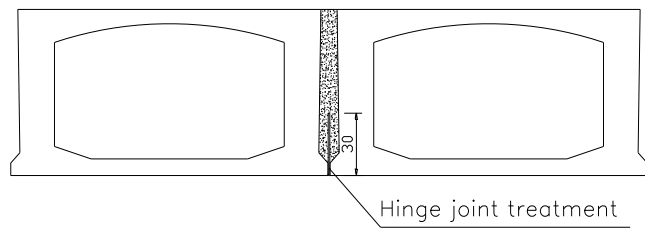

Figure 2. Cross section of drilling

\subsection{Sealing seams}

The purpose of sealing seams is to prevent glue from leaking during the first injection. According to the situation of diseases, the sealing seams are divided into the wood sealing and the PVC plate sealing.

When the displacement difference of hinge joints on both sides is less than $3 \mathrm{~mm}$, the wood sealing can be used. The width of wood can be a little more than the width of seam. With a hammer, wood is smashed into seams to ensure the close contact. After the wood-sealing, the steel sheets should be used to fix the joints of wood and the middle of a long wood in the way of horse riding nail in order to avoid wood to be extruded during the first injection. Wood sealing is shown in Figure 3.

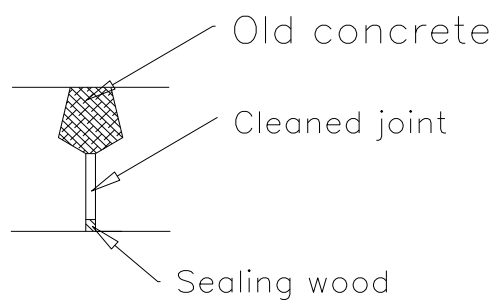

Figure 3. Wood Sealing
When the displacement difference of hinge joints on both sides is more than $3 \mathrm{~mm}$, PVC plate sealing should be used, which is to glue plastic plate on the bottom of hinge joint, and then use the $6 \mathrm{~mm}$ expansion bolts fix plastic plate. So a closed cavity can be formed between the hinge joint and the plate. PVC plate sealing is shown in Figure 4.

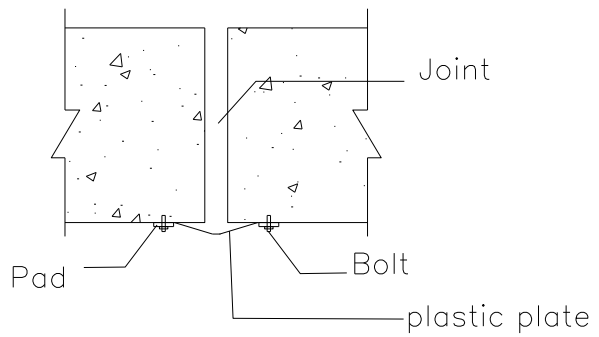

Figure 4. PVC plate sealing

\subsection{Glue injection}

The method of glue injection is high-pressure grouting, and the $\mathrm{JN}-\mathrm{G}$ series $\mathrm{A} / \mathrm{B}$ modified epoxy resin structural adhesive is adopted. The injection is finished twice.

The first injection should be begun at least two hours later when the seam sealing is completed, and the sealing adhesive has certain intensity. According to the predetermined ratio, glue is composed of group A and group B based on the proportion of 100: 50, and the amount of cement is $10 \%$ of the whole weight. The pressure of first glue injection should be controlled about $0.2 \mathrm{Mpa}$. Glue is injected into the hinge joint through the injection pipe, and the adjacent injection overflow pipe outflow with glue. The glue injection should be stopped when glue outflows through the overflow pipe, and then next injection could be taken.

The second injection is called the hinge joint glue-injection, which should be begun after at least 6 hours after the first glue-injection, and it uses pure adhesive without cement. At first, seal the overflow pipe, and then inject glue through all the injection pipes. According to the theoretical value of glue, it's injected by the injection pipe, and the condition of beam and deck should be observed. The hinge joints without longitudinal cracks should be injected until the leakage of glue which is from the beam end or pressure beyond the range of $0.2 \mathrm{MPa} \sim 0.5 \mathrm{MPa}$, and then the injection should be maintained for 15 minutes.

\subsection{Supporting}

If the displacement difference among the girders is more than $5 \mathrm{~mm}$, it will affect the effect of wood or PVC plate sealing and colloid of the glue, so the supporting should be considered. The supporting can be used in the middle of plate girders by scaffolding or set wooden supports. The minimum length of scaf- 
folding is $2 \mathrm{~m}$, or at least three wooden supports should be set, and the length of scaffold and the number of supports are increased accordingly with the increase of span. Single point supporting beam must be prohibited at the mid span in order to avoid too much bending moment and the roof cracking.

\subsection{Measures of strengthening the transverse con- nection}

Because of the glue-injection, the transverse connection between each beam is changed from concrete to glue. Due to the physical characteristics of the glue itself, the glue is generally used with the adhesive steel plate or carbon fiber cloth in the reinforcement of bridge in order to achieve a better effect of reinforcement.

\section{CALCULATION AND ANALYSIS OF REIN- FORCEMENT}

\subsection{Analysis of whole-bridge reinforcement}

A plate girder bridge with hinge joint diseases, whose superstructure is a simple assembly supported hollow plate and it is shown in Figure 5. The main diseases of the bridge are local cracking, seepage and surface whiting of hinge joints $1 \# \sim 7 \#$. Both sides of the hinge joint $3 \#$ are failure and making it a single plate bearing. The Hinge joint is diseased in the cross-sectional is shown in Figure 6:

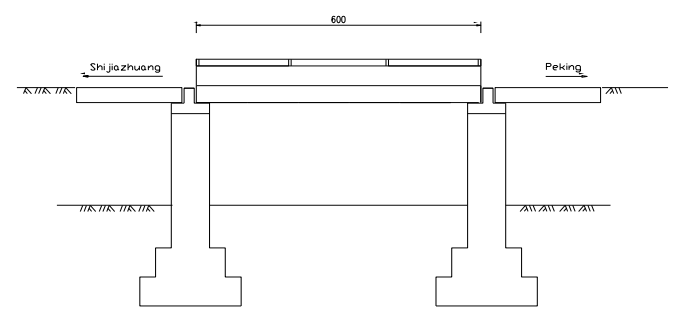

Figure 5. Elevation drawing

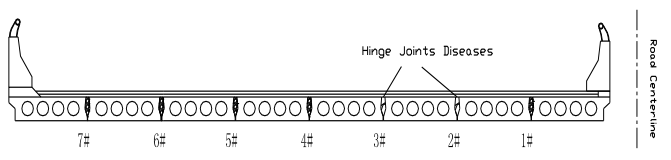

Figure 6. Hinge joints diseases schematic

According to the original design drawings to build the finite element model, the material of hollow plate is $\mathrm{C} 40$ concrete, and the material of hinge joints is the 12.5 mortar. Bridge pavement is $12 \mathrm{~cm}$ and composed of the upper asphalt concrete which is $7 \mathrm{~cm}$ and the waterproof concrete which is $5 \mathrm{~cm}$ high. According to the classical hinged plate method, the plates are connected together relying on the hinge joints, but the hinge joints only transfer the shear and do not transfer the moment. And the hinge joints with diseases do not transfer force. The finite element models of the disease bridge and the reinforced bridge are established, and the mid-span deflection in the design loads and the deflection difference of adjacent beams are respectively shown in Tables 1 2 and Figures 7 8.

Table 1. Deflections of beams in mid-span.

\begin{tabular}{lll}
\hline \multirow{2}{*}{ Condition } & Disease Bridge & Reinforced Bridge \\
& $\mathrm{mm}$ & $\mathrm{mm}$ \\
\hline $1 \#$ & -0.23 & -0.41 \\
$2 \#$ & -1.14 & -0.93 \\
$3 \#$ & -2.27 & -1.21 \\
$4 \#$ & -0.84 & -1.42 \\
$5 \#$ & -1.04 & -1.21 \\
$6 \#$ & -1.38 & -0.91 \\
$7 \#$ & -0.58 & -0.41 \\
$8 \#$ & -0.27 & -0.41 \\
\hline
\end{tabular}

Table2. Deflection differences

\begin{tabular}{|c|c|c|}
\hline $\begin{array}{c}\text { Displacement } \\
\text { Difference }\end{array}$ & $\frac{\text { Disease Bridge }}{\mathrm{mm}}$ & $\begin{array}{l}\text { Reinforced Bridge } \\
\mathrm{mm}\end{array}$ \\
\hline $1 \# \& 2 \#$ & -0.91 & -0.52 \\
\hline $2 \# \& 3 \#$ & -1.13 & -0.28 \\
\hline $3 \# \& 4 \#$ & -1.43 & -0.21 \\
\hline $4 \# \& 5 \#$ & -0.2 & -0.21 \\
\hline $5 \# \& 6 \#$ & -0.34 & -0.3 \\
\hline $6 \# \& 7 \#$ & -0.8 & -0.5 \\
\hline 7\#\&8\# & -0.3 & -0.2 \\
\hline
\end{tabular}

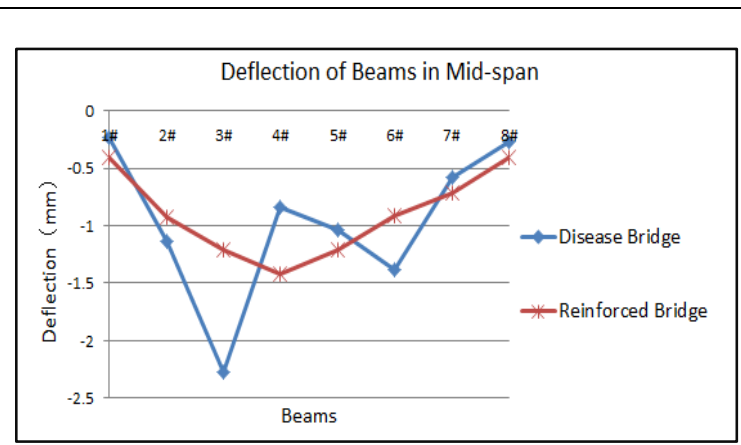

Figure 7. Deflections of beams in mid-span.

According to the chart mentioned earlier, it can be shown that the transverse distribution of deflection will become uneven if the hollow plate bridge suffers hinge joint diseases. The maximum deflection of beam $3 \#$ whose single plate is $2.27 \mathrm{~mm}$, and the displacement difference between the $3 \#$ beam and the beam $4 \#$ is $1.43 \mathrm{~mm}$ which is also the maximum deflection. After the reinforcement, the mid-span displacement is decreased, and the maximum deflection is changed 


\section{MATEC Web of Conferences}

from beam $3 \#$ which is $2.27 \mathrm{~mm}$ to beam $5 \#$ which is $1.42 \mathrm{~mm}$. The transverse distribution is more uniform, and the deflection difference of adjacent plates is significantly reduced.

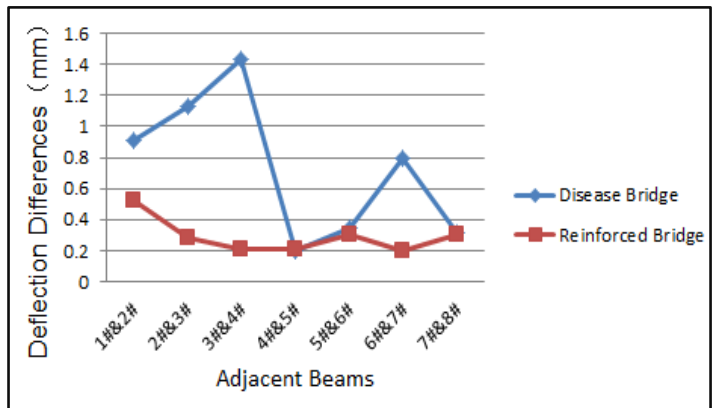

Figure 8. Deflection differences of adjacent beams

\subsection{Analysis of hinge joint local stress}

Based on the overall model, a sub-model of hinge joint is separated for analyzing the local stress. In the entity model, reinforcing materials are the pouring sealant whose mechanical property is similar to the epoxy resin material. The reference to the relevant norms of the elastic modulus is $1000 \mathrm{MPa}$, the tensile strength is $30 \mathrm{MPa}$, and the compressive strength is $50 \mathrm{MPa}$. The most disadvantageous vehicle load is applied on sections of the middle span; it's just as the overall model. In another model, A3 steel of $8 \mathrm{~mm}$ is added to the bottom flange of hinge joints and those models are shown in Figure 9:

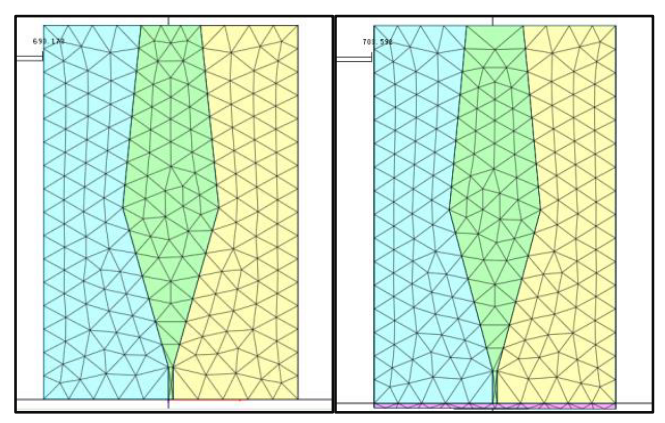

Figure 9. Reinforcement sections without or with steel

In order to be same with the overall model, the displacement of $1.39 \mathrm{~cm}$ is applied on section as an overall model. Then, we can obtain the stress distribution in the mid-span section, which is shown in Figure 10. The local stress of model without steel is shown in Figure 11. And the local stress of model with steel is shown in Figure 12.

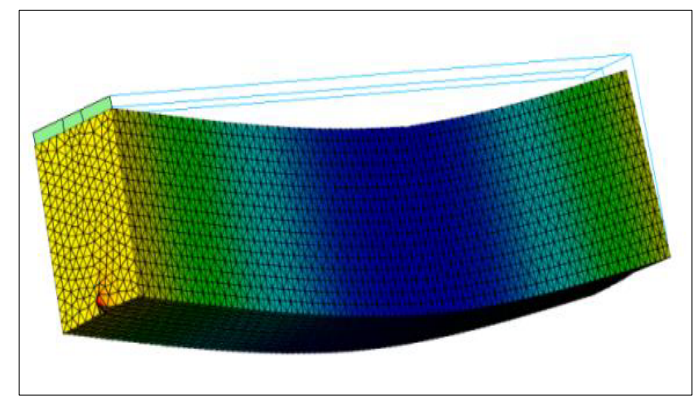

Figure 10. Deformation of sub-model

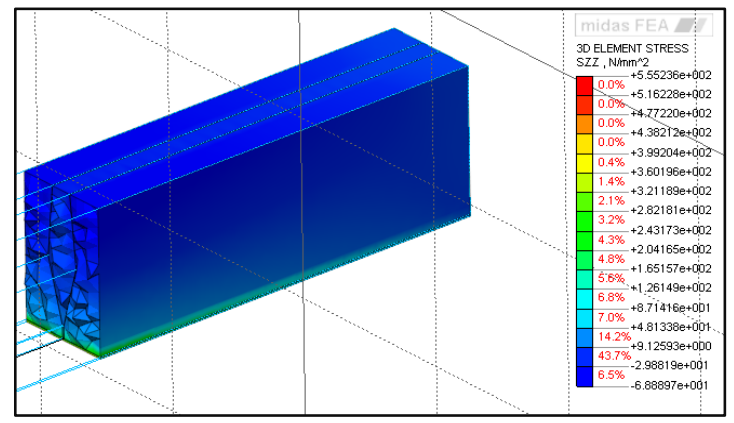

Figure 11. Structural stress without steel.

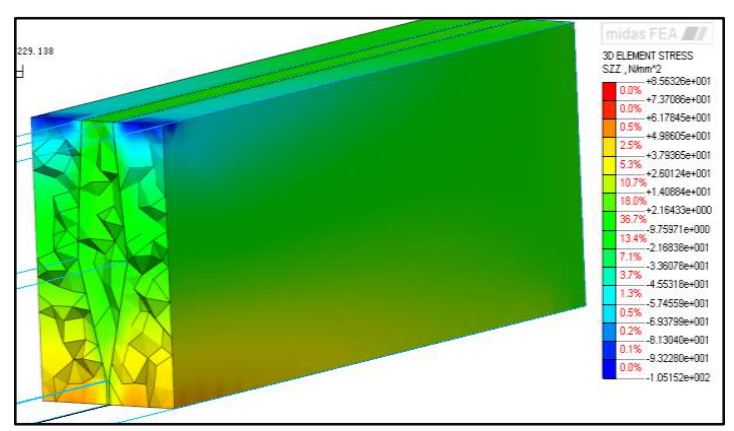

Figure 12. Structural stress with steel

According to the stress drawing when hinge joints do not paste steel, the tensile stress of the bottom flange reaches $37 \mathrm{MPa}$, which has exceeded the ultimate tensile $(30 \mathrm{MPa})$ of pouring sealant $30 \mathrm{MPa}$. When pasting the steel, the section stresses in the mid-span are redistributed, and the steel in the bottom flange will share more tensile stress. So the hinge joint is in the state of compression and the value shall meet the requirements of the code.

Based on the analysis mentioned earlier, the steel 
can not only strengthen effects of the hinge joints reinforcement and contribute to the force of perfusion adhesive, but also make the hinge joints fully play the role of "hinge" and improve the ability of hinge joints transferring lateral loads, which can completely eliminate the single plate bearing.

\section{EFFECT EVALUATION}

According to the construction process of the glue-injection, a bridge was reinforced by glue-injection. The appearance of hinge joints is good, and no cracks, water seepage or new traces of water seepage are found. No new cracks appear on the deck. The comparison of hinge joint's appearance which is before or after the reinforcement is shown in Figures 13 14:

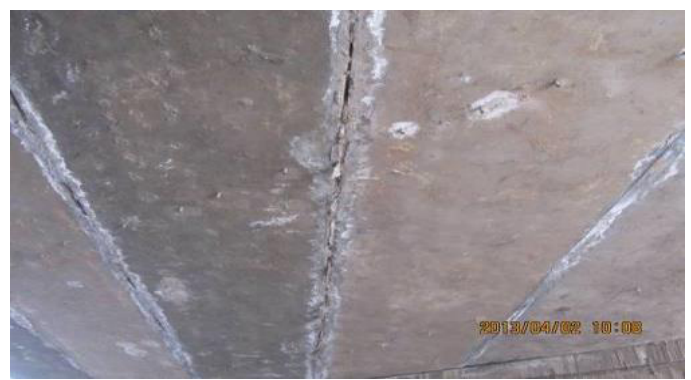

Figure 13. Before the reinforcement

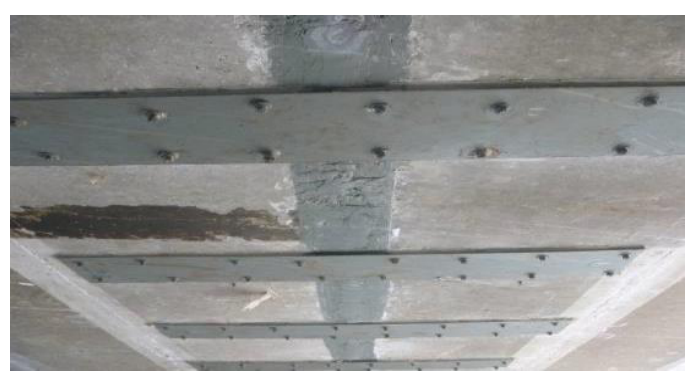

Figure 14. After the reinforcement

In order to verify effects of the reinforcement method, the dynamic deflection in the mid span of hollow plates is monitored before and after the reinforcement. Displacement meters are set based on the "Single Plate Bearing" girder which is shown in Figure15. Through the data collection and analysis, the maximum displacements of "single plate bearing" girder and maximum displacement difference between two beams are concluded, which can reflect the hinge joint's working state.
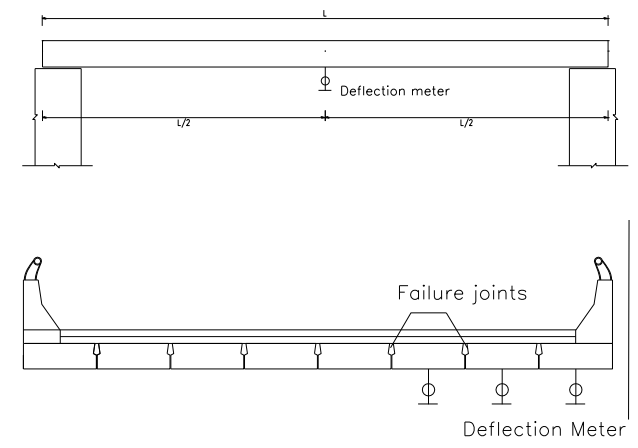

Figure 15. Arrangement of measuring points

The deflection curve graph of beams $1 \# \sim 3 \#$ and the curve graph of displacement difference between two beams are shown in Figures 16 17:

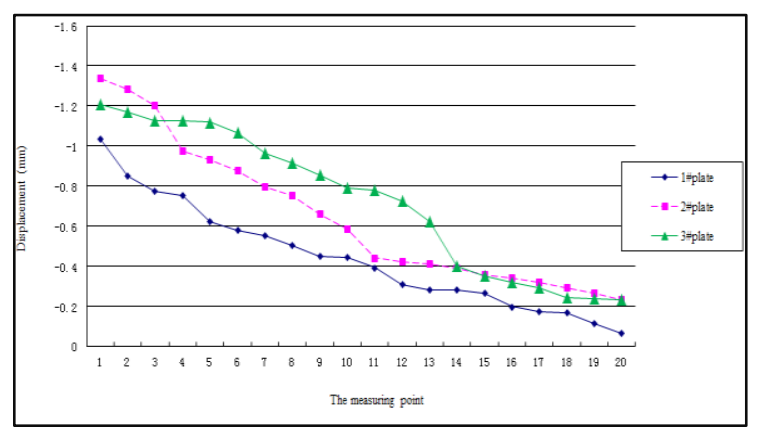

Figure 16. Deflection curves of beams $1 \# \sim 3 \#$

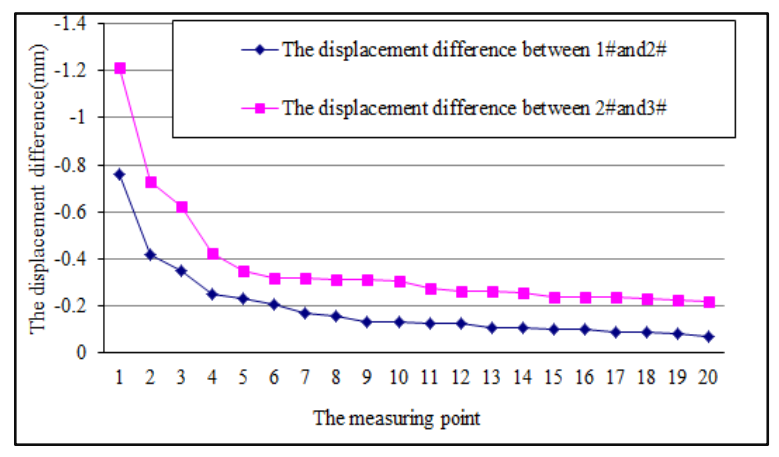

Figure 17. Difference between two beams

According to the deflection curve, we can conclude that the deflections of beam $2 \#$ and beam $3 \#$ are significantly larger than other deflections, and they are respectively $-1.337 \mathrm{~mm}$ and $-1.209 \mathrm{~mm}$. According to 


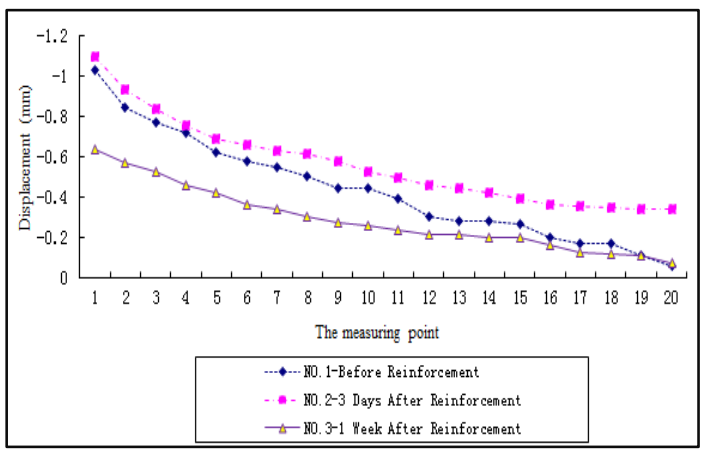

Figure 18. Displacements of beam 1\#

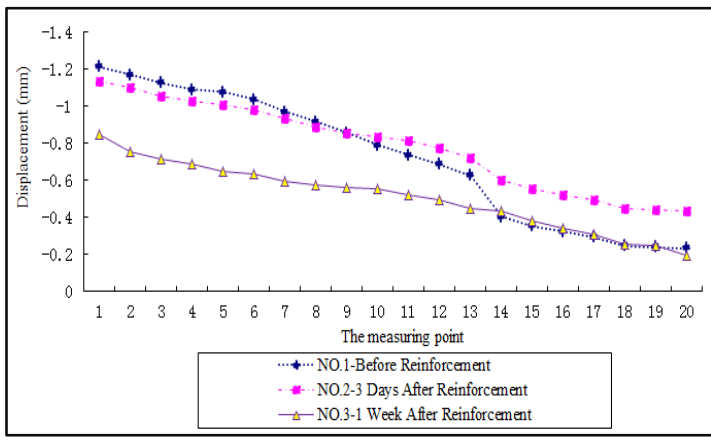

Figure 20. Displacements of beam 3\#

the graph of displacement difference, we can conclude that the 1-1\# hinge joint 1-1\# is in a good condition with the displacement difference which is $-0.761 \mathrm{~mm}$. And hinge joints 2\# and 3\# are respectively $-1.21 \mathrm{~mm}$ and $-1.24 \mathrm{~mm}$.

In order to compare the effect, the deflection of each beam is detected and the main data is shown in Figures 18-21.

According to the graph, we can conclude that the deflections of each beam are significantly reduced, they are respectively $42 \%, 19 \%$ and $30 \%$ The distribution of overall bridges has a very good improvement, which can strengthen the cooperation of each beam. The deflection of the first detection of reinforcement (within a week after the reinforcement) is significantly decreased than before, which reflects the reinforcement method that has a better timeliness.

\section{SUMMARY}

In this paper, a treatment of hinge joint diseases without traffic interruption is presented as there are a large number of damaged hinge joints in plate girder bridges at present. According to the local stress of hinge joints, the key points in each step are summarized, and they practically guide the bridge reinforcement.

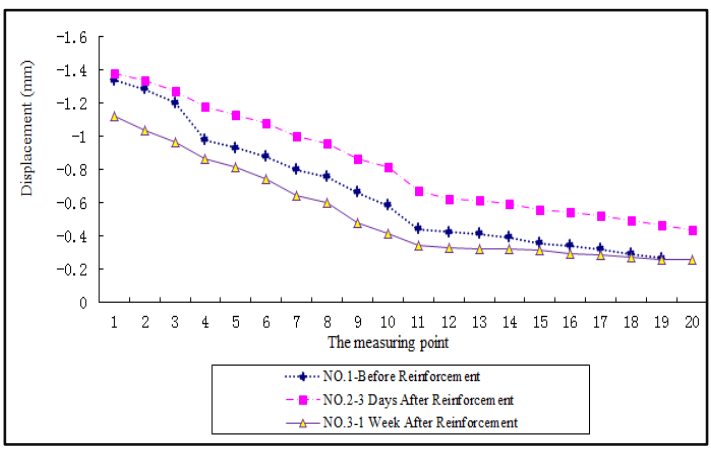

Figure 19. Displacements of beam 2\#

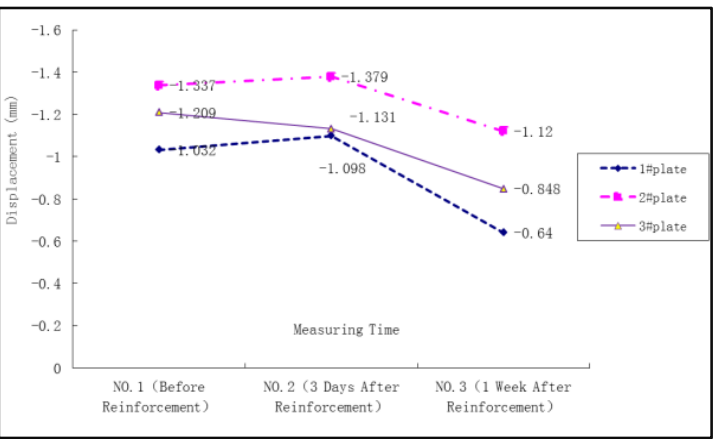

Figure 21. Minimum displacements of beams 1\# 3\#

Through the comparisons of test data before or after the reinforcement, the main conclusions are shown as follows:

1. The construction method of glue-injection can be adopted without traffic interruptions, and it is convenient. Through the example, the method is a practical maneuverability.

2. The classic method of articulated slab can be used for the calculation of hinge joint diseases and reinforcement of the bridge. And the calculated values and measured values are the same.

3. According to the comparisons of appearance and deflection of the disease bridge before or after the reinforcement, the construction method has a good effect on the reinforcement of plate girder bridge with a single plate bearing.

4. The construction method without traffic interruptions is convenient and timely, which can be promoted in the bridge reinforcement with similar diseases.

\section{REFERENCES}

[1] Qiao Xueli. 2008. Study on the Hinged Joint Destruct Reasons of Hollow Plank Girder Bridge and the Preventable Measures. Xi'an: Chang'an University. 
[2] Zhong Yongfeng. 2008. Study on the Hinge Joint Model Experiment of Hollow Slab Beam Bridge. Xi'an: Chang'an University, 2008.

[3] Fang Tao. 2010. Application of Chemical Grouting Seam in Consolidation of Simply Supported Plate Girder Bridge Hinge. Highway Traffic Science and Technology. 10(2): 93-96.

[4] Zhao Man. \& Wang Xinmin. 2004. Numerical Analysis on "Single Plate Bearing" of Plate Girder Bridge. China Safety Science Journal. 14(11): 25-29.

[5] Chen Xiaoqiang \& Zhao Jiajun. 2004. Disease Analysis and Reinfoorement of Plate Giders Damaged by Hinge Joint. Modern Transportation Technology. 10(1): 46-48. 